\title{
Correction to: Planetary carambolage: The evolutionary political economy of technology, nature and work
}

\author{
K. Gruszka ${ }^{1} \cdot$ M. Scholz-Wäckerle ${ }^{2} \cdot$ E. Aigner $^{3}$ \\ Published online: 8 December 2020 \\ (C) The Author(s) 2020
}

\section{Correction to: Review of Evolutionary Political Economy https://doi.org/10.1007/s43253-020-00030-3}

The original version of this article unfortunately contained a mistake. All citations of Hannapi (2020) are misspelled; it should be Hanappi (2020). The original article has been corrected.

The online version of the original article can be found at https://oi.org/10.1007/s43253-020-00030-3

M. Scholz-Wäckerle

manuel.scholz-waeckerle@wu.ac.at

K. Gruszka

katarzyna.gruszka@wu.ac.at

E. Aigner

ernest.aigner@wu.ac.at

1 Institute for Ecological Economics, Department of Socioeconomics, Vienna University of Economics and Business, Wien, Austria

2 Department of Socioeconomics, Vienna University of Economics and Business, Wien, Austria

3 Institute for Economic Geography and GIScience, Department of Socioeconomics, Vienna University of Economics and Business, Wien, Austria 